\title{
A história de vida um sujeito com a Síndrome de Klinefelter
}

\author{
Michell Pedruzzi Mendes Araújo* \\ Rogério Drago ${ }^{* *}$
}

\section{Resumo}

Este estudo objetiva compreender a história de vida de um sujeito com a Síndrome de Klinefelter, uma síndrome rara restrita ao sexo masculino. A metodologia utilizada para alcançar esse objetivo foi a história de vida, alicerçada pelos pressupostos da perspectiva sócio-histórica e no paradigma indiciário de Ginzburg. Nessa pesquisa, os encontros com um sujeito que possui a síndrome de Klinefelter são descritos e analisados, levando-se em conta os aspectos subjetivos. Nesses encontros, várias narrativas foram ouvidas para compor a história de vida do sujeito pesquisado: a do próprio Ramon, da sua mãe Marlene e das professoras da APAE e da Educação de Jovens e Adultos. Para colher os dados, recorreu-se às entrevistas biográficas semiestruturadas. Os dados obtidos foram analisados levando-se em conta o contexto histórico e social de Ramon, assim, foram observadas as relaçóes dialógicas estabelecidas por Ramon com seus pares. Nesse sentido, a partir dessa pesquisa, pôde-se perceber que para além do biológico, Ramon é um ser social, cultural, que aprende, apreende e que, para além disso, muito ensina.

Palavras-chave: Síndrome de Klinefelter; Perspectiva histórico-cultural; Subjetividade.

* Doutorando em Biologia pela Universidade Federal do Espírito Santo,Vitória, Espírito Santo, Brasil.

** Doutor em Ciências Humanas - Educação pela PUC-Rio,Rio de Janeiro, Rio de Janeiro, Brasil. 


\section{Life story a subject with Syndrome Klinefelter}

\section{Abstract}

This study aims to understand the life story of a man with Klinefelter's syndrome, a rare restricted to male syndrome. The methodology used to achieve this goal was the story of life, supported by assumptions of socio-historical perspective and the evidential paradigm Ginzburg. In this research, meetings with a guy who has the Klinefelter syndrome are described and analyzed, taking into account the subjective aspects. In these meetings, several stories were heard to compose the subject's life story researched: the Ramon himself, his mother Marlene and teachers APAE and Youth and Adult Education. To collect the data, we used the biographic semi-structured interviews. The data were analyzed taking into account the historical and social context of Ramon thus dialogical relations established by Ramon with his peers were observed. In this sense, from this research, it was possible to realize that beyond the biological, Ramon is a social being, cultural, learning, learns and that, moreover, has much to teach.

Keywords: Klinefelter's syndrome; Historical-cultural perspective; Subjectivity.

\section{Introdução}

Ramon é o meu tesouro! O que seria da minha vida se não tivesse o Ramon? Ele é o motivo para eu lutar. Eu corri atrás de muita coisa, por mim e por ele! Sem ele, não estaria com essa obra nova (construção da nova casa no centro de Domingos Martins). Talvez, até hoje, não existisse a APAE e a EJA no município. Muita coisa não existiria se não tivesse o Ramon, do jeitinho que ele é... (MARLENE, mãe de Ramon, sujeito com a síndrome de Klinefelter).

Este trabalho traz à tona a história de vida de um sujeito, o Ramon, que possui uma síndrome bem peculiar: a síndrome de Klinefelter. A partir da fala da mãe supracitada emergem questionamentos: O que é a Síndrome de Klinefelter? Será que as histórias dos sujeitos com deficiência, em especial com a Síndrome de Klinefelter, têm sido ouvidas? E esses sujeitos se encerram nas suas características biológicas, ou são sujeitos sociais e culturais? Essas indagaçôes motivaram a execução desse estudo.

Pode-se definir a síndrome de Klinefelter, genotipicamente falando, como uma alteração cromossômica numérica envolvendo os cromossomos sexuais, nesse caso envolve o cromossomo X. Nessa síndrome, os indivíduos apresentam em seu cariótipo, pelo menos, um cromossomo sexual a mais (o cromossomo $\mathrm{X}$ ), o que reflete em diversas alteraçóes fenotípicas (ARAÚJO, 2012).

Sabe-se que os indivíduos com a referida síndrome são exclusivamente do sexo masculino, mas podem apresentar algumas características sexuais secundárias femininas tais como o desenvolvimento de mamas, a distribuição dos pelos pubianos, 
a tonalidade da voz, dentre outras. Em alguns indivíduos, os caracteres estão mais acentuados do que em outros. Isso ocorre devido ao cromossomo X extranumerário (ARAÚJO, 2014).

O fenótipo mais comum consiste em um hipogonadismo ${ }^{1}$ hipergonadotrófico $^{2}$, azoospermia ${ }^{3}$, atrofia testicular de consistência firme, hipodesenvolvimento dos caracteres sexuais secundários, geralmente associado à ginecomastia e desproporção morfológica entre o tronco e os membros. Nas variantes mais extremas se observam outras anomalias muito marcadas, particularmente a de nível neuropsiquiátrico (CARRASQUINHO et al., 2006).

Com relação aos aspectos cognitivos, os sujeitos com a síndrome podem apresentar: dificuldade na fala, diminuição da memória em curto prazo, diminuição das habilidades de recuperação de dados, alta incidência de dislexia, déficit de atençáo, agressividade acentuada e desordens psiquiátricas tais como neurose, psicose e depressão (SMITH \& BREMNER, 1998).

A produção bibliográfica no Brasil acerca da síndrome de Klinefelter ainda é incipiente. Isso é evidenciado quando se faz um levantamento de produção presente no banco de teses e dissertaçóes da CAPES. Por meio desse levantamento foi possível verificar a existência de três dissertaçóes cuja temática aborda de maneira superficial a síndrome em estudo, mas cabe salientar que em nenhuma dessas produções a síndrome de Klinefelter é o foco principal do estudo. Outro dado que merece enfoque é que em nenhum desses estudos os aspectos relacionados ao processo de aprendizagem e desenvolvimento são considerados.

Além do banco da CAPES, foi realizada uma pesquisa em vários sítios da internet do Brasil e de um contexto global. Constatamos que quase toda produção bibliográfica acerca da síndrome de Klinefelter ainda se restringe a área médica, com enfoque apenas na descrição da síndrome, no tratamento e nos sintomas clínicos. Só localizamos uma dissertação de mestrado de Vicente (2011), produzido em Lisboa (Portugal), que aborda aspectos tangíveis às competências comunicativas (aspectos cognitivos) no contexto escolar.

Em síntese, diante do exposto e encontrado, salienta-se que o presente estudo se justifica pela necessidade real e urgente de pesquisas na área da educação que abordem essa temática. Sabe-se que os sujeitos com os diversos tipos de síndromes estão inseridos no contexto escolar, mas inúmeras vezes estes só são visibilizados pelos pesquisadores da área médica que apresentam em seus estudos sujeitos medicalizados.

Tendo em vista o que foi supracitado, este estudo tem como objetivo geral, compreender, pelo discurso do outro, uma parte da trajetória de vida de um sujeito com a síndrome de Klinefelter. Como objetivos específicos, buscou-se: Entender se/ como ocorreu a inclusão do sujeito com a síndrome de Klinefelter no âmbito da escola comum; Entender como se deu a participação da família desse sujeito no processo inclusivo social, familiar e escolar; Compreender como as relaçóes interpessoais podem contribuir para a formaçáo e o reconhecimento da subjetividade do sujeito com a síndrome de Klinefelter. 


\section{A perspectiva socio-histórica como orientadora das histórias de vida}

Este estudo está calcado na teoria sócio-histórica, embasada no materialismo dialético, cujos estudos norteadores da pesquisa serão os de Vigotski, Pino, González Rey, Souza, dentre outros pesquisadores e autores que imprimem em seus textos raízes sócio-históricas, observando a mutabilidade dos processos.

Nesse sentido, é importante destacar que a teoria sócio-histórica, pautada no materialismo dialético, nos fornece valiosas contribuiçôes no que concerne à análise da história de vida de um sujeito com uma síndrome rara, que está inserido no contexto da escola comum e recebe atendimento educacional especializado na escola comum (no contexto da EJA ${ }^{4}$ ) e na APAE.

Cabe dizer, nesse momento, que a escolha por essa opção teórica se deu porque essa nos remete ao estudo dos processos em uma perspectiva incessante de mudança. Assim, a nossa tarefa como pesquisador está atrelada à reconstrução da origem e do curso de desenvolvimento do comportamento e da ciência. Buscamos nesse processo, entender a história dos processos compreender as suas mudanças qualitativas e quantitativas. Conforme enfatiza Marx, as mudanças históricas na sociedade e na vida material produzem mudanças na natureza humana (VIGOTSKI, 2007).

O materialismo dialético possibilitará a ampliação do nosso conhecimento acerca dos processos que ocorrem em determinados contextos. Desse modo, tem-se uma visão do meio ambiente constituído por contextos culturais e históricos em constante transformação, que moldam os seres biológicos (VIGOTSKI, 2007).

Diante do que foi exposto, cabe ressaltar que nesse estudo com um sujeito com a síndrome de Klinefelter, buscamos entender a constituição subjetiva desse sujeito com deficiência nas e pelas relaçóes sociais, enumerando processos intensamente dialéticos: natureza e cultura. Assim, para compreender processos naturais e culturais, concordamos com Pino (2005, p. 268) quando destaca que:

$$
\begin{aligned}
& \text { Se a natureza precede a cultura, a cultura supóe a natureza, porque } \\
& \text { ela é, em última instância, a própria natureza transformada em } \\
& \text { cultura, mas uma cultura que, sem deixar de ser natureza, torna-se } \\
& \text { algo novo. Eu a chamaria uma natureza humanizada. }
\end{aligned}
$$

Desse modo, entendemos que o homem possui uma natureza, ou seja, sua constituição gênica, nascendo biologicamente Homo sapiens sapiens. Porém, ao se relacionar com os outros em um intenso processo de mediaçáo, este ser nasce culturalmente e é integrado socialmente. Assim, para compreender o processo de constituição subjetiva do ser humano devemos levar em conta a complexidade das relaçôes sociais e culturais.

No que tange às relaçóes interpessoais para o processo de construção identitária e subjetiva do sujeito com deficiência, cabe destacar que "ao observarmos as interaçóes sociais e os enunciados que emergem na vida cotidiana constatamos a nossa necessidade absoluta do outro. Nossa individualidade não teria existência se o outro não a criasse" (SOUZA, 2003, p. 83). Entendemos, nesse sentido, que "a compreen- 
são que o sujeito tem de si se constitui por meio do olhar e da palavra do outro. Cada um de nós ocupa um lugar determinado no espaço e deste lugar único revelamos o nosso modo de ver o outro e o mundo físico que nos envolve" (SOUZA, 2003, p. 83). Tangenciando com o que já foi exposto, é importante dizer que

ser significa ser para o outro e, por meio do outro, para si próprio. É com o olhar do outro que me comunico com meu interior. Tudo o que diz respeito a mim chega a minha consciência através do olhar e da palavra do outro, ou seja, o despertar da minha consciência se realiza na interação com a consciência alheia (SOUZA, 2003, p. 83).

Por fim, cabe salientar que o sujeito da nossa pesquisa é um ser social, dessa maneira, ao se integrar à sociedade, pleno de suas capacidades, esse vai se socializando à medida que vai modificando e refinando sua identidade, bem como percebendo o seu papel na sociedade.

Assim, a relação que o indivíduo mantém com os outros do processo ensino -aprendizagem, bem como o modo como se elaboram as hipóteses e a apropriação do conhecimento cognitivo vêm ao encontro da teoria sócio-histórica (DRAGO, 1999).

\section{Encontrando um caminho metodológico para contar uma história de vida...}

O modo de pesquisa que mais contribui para o alcance dos objetivos centrais desse trabalho é a história de vida, uma vez que esse método "tem como consequência tirar o pesquisador de seu pedestal de "dono do saber" e ouvir o que o sujeito tem a dizer sobre ele mesmo: o que ele acredita que seja importante sobre sua vida" (GLAT, 2009, p. 30). Cabe salientar que nesse tipo de pesquisa dá-se voz aos sujeitos do estudo, fala-se com os sujeitos e náo sobre eles. Por fim, cabe dizer que o ponto de vista nesse tipo de pesquisa é próprio do sujeito e não do pesquisador.

A escolha por essa metodologia se deu porque possibilita uma abordagem histórica muito mais precisa/exitosa, além de oferecer flexibilidade ímpar, considerando a promoção da capacidade de dominar a evidência humana exatamente onde ela é necessária. Trata-se de uma tentativa de oferecer escuta e, ainda mais, "de dar voz àqueles cujo discurso foi calado ou teve pouca influência no discurso dominante" (PARANÁ, 1996, p. 317).

Nesse contexto, o processo de contar sua história de vida pode levar ao indivíduo com a síndrome compreender o próprio eu. De acordo com Thomson (1997, p.57), "ao narrar uma história, identificamos o que pensamos que éramos no passado, quem pensamos ser no presente e o que gostaríamos de ser [no futuro]".

Nesse contexto, é importante dizer que trabalhamos nesse estudo com a pesquisa qualitativa em uma abordagem sócio-histórica, porque nos preocupamos em compreender os fenômenos investigados, descrevendo-os e procurando as suas possíveis relaçóes, integrando o social com o individual. A fundamentação desta pode 
ser observada em Vigotski, quando consideramos que todo conhecimento é sempre construído na inter-relação das pessoas. Desse modo, produzir conhecimento a partir de uma pesquisa é, pois, assumir a perspectiva da aprendizagem como processo social compartilhado e gerador de desenvolvimento (FREITAS, 2002).

Vale lembrar que nesse estudo pesquisamos os fatos considerando as minúcias, os resquícios. Nesse sentido, Vigotski (2004), no texto Método de investigação, chamou a atenção para a necessidade da valorização cotidiana de um processo e as possibilidades do conhecimento científico produzido a partir de um fragmento ou resíduo ou vestígio. Podemos, dessa forma, desenvolver pesquisas na perspectiva sócio-histórica, atrelando os pressupostos vigotskianos ao pensamento do paradigma indiciário de Ginzburg (1989).

Assim, o paradigma ou método indiciário de Ginzburg (1989) nos auxiliou a fazer pesquisa na perspectiva sócio-histórica, com a utilização da metodologia história de vida, uma vez que alguns pormenores, em um contexto global, serviram como base para compreendermos os processos de formação da constituição identitária de um sujeito com uma síndrome.

A entrevista utilizada foi um tipo de semiestruturada denominada entrevista biográfica, uma vez que esta permitiu maior liberdade às características individuais dos entrevistados.

\section{Conhecendo um pouco da história de vida de Ramon, sujeito com a Síndrome de Klinefelter}

No primeiro momento em que conhecemos Ramon, devido à fala bem peculiar desse sujeito, pensamos em ouvir a voz da mãe Marlene 5 e a partir daí, conhecer a trajetória de vida dele. No entanto, no primeiro encontro mesmo, passamos a ter um contato mais íntimo com ele e percebemos que apesar de a fala dele não ser articulada, poderíamos sim ouvir também a voz daquele sujeito, entendendo as nuances de sua linguagem peculiar.

Dessa maneira, nesse estudo, buscamos entender a trajetória de vida de Ramon, não somente a partir da mãe, mas pelas narrativas do próprio Ramon e das professoras que mantém intrínseco contato com ele. Tentamos conversar com o pai, mas não foi possível. Sob esse prisma, conseguimos entender a subjetividade de Ramon a partir das relaçóes dialógicas que ele estabelece com os outros. Nesse sentido, concordamos com Vigotski (1997, p. 372) quando ressalta que "cada pessoa é em maior ou menor grau o modelo da sociedade, ou melhor, da classe a que pertence, já que nela se reflete a totalidade das relaçôes sociais".

Ramon, na atualidade ${ }^{6}$ é um rapaz que possui 22 anos. Nasceu no dia 22 de abril de 1991 no município de Domingos Martins-ES. Seus pais já eram casados quando a máe dele engravidou. $\mathrm{Na}$ ocasiáo de seu nascimento, seu pai possuía 33 anos e sua mãe, 26 anos. A mãe relatou que já estava praticamente sem líquido e que já estava sangrando, no momento que seu filho nasceu. Ou seja, o parto de Ramon foi prolongado e atípico. 
Ramon nasceu com $2,450 \mathrm{Kg}$ e $45 \mathrm{~cm}$. Era uma criança pequena e magra e tinha saúde normal de acordo com a observação médica. A mãe relatou que, após alguns dias, o seu filho começou a engordar e a desenvolver bem.

Cabe ressaltar que Ramon não mamou, não devido à ausência de leite materno, mas a mãe relatou que o filho parecia ter nojo dessa forma de alimentação. Assim, passou a tomar mamadeira desde recém-nascido, tomava engrossante de leite e se desenvolveu bem.

Porém, com o tempo, de 6 meses a 1 ano de idade, os pais e os familiares observaram que Ramon era muito "molinho", ou seja, não sentava, não andava, nem vocalizava. Perceberam que existia um hipodesenvolvimento ${ }^{7}$.

Nesse sentido, Marlene, devido a sugestôes de amigos, resolveu mudar de pediatra, haja vista que o médico anterior parecia não se preocupar com o hipodesenvolvimento do paciente. Então, Marlene passou a levar Ramon, após um ano de idade, para ser atendido com um profissional de saúde no município de Vila Velha/ ES. Esse médico, o encaminhou para um neuropediatra e para um fisioterapeuta. A máe relatou que esse pediatra disse que Ramon necessitava de estimulação e ressaltou sobre a importância de um acompanhamento em uma instituição especializada como a APAE ou PESTALOZZI.

Devido à intensa estimulação, Ramon deu seus primeiros passos com dois anos e quatro meses. Fazia atendimento na Pestalozzi e não tomava nenhuma medicação. Era acompanhado com um fonoaudiólogo, com uma psicóloga e com outros especialistas. Apresentava um desenvolvimento gradual e lento, devido ao intenso processo de estimulaçáo. Frequentou a instituição Pestalozzi dos três aos sete anos no município de Marechal Floriano-ES.

No ano de 1998, Ramon começou a frequentar a APAE no município de Domingos Martins. Cabe destacar que ele, nesse contexto, possuía sete anos. Ramon, somente passou a frequentar a APAE nesse ano porque foi o ano de inauguração dessa instituição no município. Nesse processo de conquista da APAE no município, Marlene e Arlete, professora de Ramon, tiveram extensas contribuiçóes. Houve muita mobilização das famílias dos sujeitos com deficiência do município e de professores para que a APAE fosse instalada. Sob a ótica de Marlene, a porta principal para o desenvolvimento de Ramon foi a conquista da APAE no município. Cabe destacar que inúmeras pessoas eram contra a criação dessa instituição no município, por conta do preconceito e da falta de conhecimento. Achavam que era uma escola para "doidos" e "abobados", que representava uma ameaça para os cidadãos ditos normais.

Durante esse intenso processo de mobilização, Marlene resolveu tirar sua carteira de motorista e passou a levar Ramon a todos os espaços necessários.

Quanto à escola comum, Ramon frequentou pouco. Iniciou esse processo de estudo no ano de 1997, quando possuía seis anos. No que tange às escolas de rede privada, Ramon não se adaptou bem. A mãe disse que a inclusão não ocorreu, de 
fato. Além disso, na época da inserção de Ramon, havia muito preconceito por parte das famílias dos indivíduos sem deficiência. Marlene ressalta que muitos pais não queriam que os filhos deles estudassem com um menino que babava e que beliscava os outros.

Diante do exposto, Marlene resolveu tirar seu filho da instituição privada e matricular Ramon na escola pública. Matriculou seu filho na escola polivalente. Com 6 anos, estava na $1^{\text {a }}$ série. Adaptou-se bem, a mãe estava satisfeita com o trabalho na escola pública. Na fala da máe, percebe-se a importância da escola para a socializaçáo, uma vez que Ramon não avançava muito na fala e não conseguia escrever.

Ramon frequentou regularmente até a $3^{a}$ série do ensino fundamental. A partir daí, passou a ficar muito agressivo. Devido às oscilaçôes nas taxas hormonais, na puberdade, Ramon passou a ficar mais ainda agressivo. Batia em alguns colegas, beliscava os outros, machucava-se e isso foi se constituindo em uma rotina. Assim, a mãe dele resolveu tirá-lo da escola de ensino comum. Sempre o matriculava para manter o direito de frequentar a APAE, mas náo levava Ramon para a escola de ensino comum. Marlene relatou que seu filho frequentou regularmente a escola comum, o polivalente, no período de 1998 até o ano de 2000.

A partir desses picos de agressividade, Marlene passou a levá-lo intensamente em alguns especialistas como psiquiatras e psicólogos. Ela relata que durante o período de 14 a 16 anos, chegou a tomar 12 comprimidos e meio por dia. Foi o período mais crítico. $\mathrm{Na}$ atualidade, toma 04 comprimidos pela manhã e não é mais agressivo.

É importante dizer que durante esses anos todos, Ramon nunca deixou de frequentar a APAE, sempre vai e, na maioria dos anos, foi aluno da professora Arlete. De acordo com o relato dessa professora e da máe, Ramon gosta de movimento. Gosta de dançar, contar "fofocas" dos conhecidos e familiares e gosta de pintar e jogar. Não gosta de fazer nada sozinho, tanto que o atendimento, clínico ou pedagógico, sempre é realizado em duplas ou grupos. Ramon queixa-se quando a "tia Arlete" falta e reclama quando faz algo sozinho.

Até o ano de 2012, esteve matriculado na escola comum, apesar de não frequentar regularmente. Contudo, no ano de 2013, a mãe não conseguiu matriculá-lo. A escola alegou que Ramon já é maior de idade e que deveria estar inserido na EJA. Diante do exposto, a mãe conseguiu mantê-lo na APAE uma vez por semana e com algumas pessoas do município, passou a fazer uma grande pressão para se conseguir a Educação de Jovens e Adultos.

A conquista da EJA se efetivou e, até o final do ano de 2014, Ramon e sua mãe, Marlene, encontravam-se matriculados e frequentam, efetivamente, a escola na modalidade da EJA. Ramon frequenta a mesma turma da máe e recebe Atendimento Educacional Especializado- AEE, onde a professora Lisa atua com o auxílio da informática educacional. Ramon já apresenta alguns avanços. Já sabe reconhecer seu nome, mexer no mouse e ligar o computador. 
É importante destacar que Ramon ainda não foi alfabetizado, contudo, dentro das potencialidades desse sujeito, percebe-se que avanços ocorrem até o atual momento. Por exemplo, Ramon lida muito bem com os colegas, gosta de movimento de fazer trabalho em grupo. $\mathrm{Na}$ EJA, os trabalhos são direcionados desta forma, são trabalhos grupais, onde um auxilia o outro.

$\mathrm{Na}$ EJA, acompanhamos o trabalho das professoras realizado com Ramon e seus pares. A partir de nossas observaçóes a campo e das entrevistas, percebemos que as professoras desenvolvem atividades que resgatam a autonomia do Ramon. Além disso, buscam uma maturidade na fala de Ramon, que ainda é muito 'infantilizada'. Nas falas das professoras encontramos alguns indícios e registros:

Independentemente da limitação do Ramon, penso que ele será sempre capaz de fazer as atividades da escola... desde que nos adaptemos a ele e náo apenas o contrário (Professora regente-Karina).

Ramon provavelmente não terá a Marlene para sempre! Ele terá que se virar em diversos espaços... na escola, na padaria e na rua..., nos preocupamos com a autonomia dele (Professora do AEELisa).

Pudemos perceber no contexto da EJA que há uma busca pela autonomia do Ramon que foi exitosa. Ramon, a partir desse trabalho desenvolvido com/por outros profissionais da EJA, está avançando em muitos quesitos. Esse estudo desvela a importância que a APAE teve para o desenvolvimento desse sujeito, no entanto, é importante destacar que o mais indicado para uma aprendizagem e um desenvolvimento exitosos é a presença do indivíduo com a síndrome no contexto da escola comum, tendo contato com muitos profissionais e, principalmente com muitos colegas.

Esse avanço de Ramon foi verificado no contexto da EJA e nos indica que o trabalho realizado na APAE pelos mesmos profissionais durante anos pode ter inibido o desenvolvimento desse sujeito em outras dimensôes. Não estamos, nesse caminho, desmerecendo a importância da APAE, mas entendemos que para um desenvolvimento pleno de um sujeito com uma síndrome, como a de Klinefelter, há necessidade de outros olhares, outros profissionais, outros rizomas estabelecidos com outros pares. Afinal, a subjetividade de um sujeito é tecida na coletividade.

\section{Algumas tecituras}

O homem é uma criatura social, e as condições socioculturais o modificam profundamente, desenvolvendo toda uma série de novas formas e técnicas em seu comportamento (VIGOTSKI; LURIA, 1996, p. 122).

Iniciamos a tecitura de nossas consideraçôes trazendo a fala anterior de Vigotski que nos remete ao principal objetivo de nosso estudo: compreender a trajetória de vida de um sujeito com a síndrome de Klinefelter. Para compreender a trajetória de vida de Ramon, não podíamos apenas ouvir o Ramon, sujeito com a síndrome de Klinefelter, mas os OUTROS, aqueles que exercem influência sobre a construção subjetiva do ser Ramon. Afinal, Ramon só possui uma subjetividade tão peculiar porque a construiu socialmente nas relaçóes com os outros. 
Nesse contexto, concordamos com González Rey (2004, p. 141) ao afirmar que "a subjetividade é um sistema complexo que tem dois espaços de constituição permanente e inter-relacionados: o individual e o social, que se constituem de forma recíproca e, ao mesmo tempo, cada um está constituído pelo outro". Dessa maneira, é impossível a separação entre os processos sociais, nos quais se produzem a ação individual e os processos psíquicos individuais que são constituintes dessa mesma ação (GONZÁLEZ REY, 2004).

Procuramos compreender Ramon para além da síndrome, ou seja, deixamos em segundo plano, alguns aspectos típicos da síndrome (algumas rotulações impostas pela área médica) para entender as características de Ramon comuns aos OUTROS, isto porque o longo caminho do desenvolvimento do Ramon segue a direção do social para o individual (REGO, 2010). Assim, destacamos a importância do social sobre o biológico e vice-versa. Ou seja, em nossa pesquisa, entendemos as funçóes das características tipicamente humanas. Nesse contexto, consideramos nesse estudo que:

as funçóes psicológicas superiores [...], suas qualidades superiores, que são específicas do seres humanos, se manifestam originalmente como formas de conduta coletiva da criança, como forma de cooperaçáo com as outras pessoas; e só depois é que se tornam funções individuais internas da criança (VYGOTSKY, 1994, p. 353).

É claro que não podemos deixar de ressaltar a notória peculiaridade e complexidade da síndrome de Klinefelter. Os sujeitos masculinos possuem caracteres femininos e a deficiência intelectual é asseverada, em alguns casos, pela síndrome. Esses aspectos fenotípicos divergentes do esperado certamente tornam a história de vida de Ramon bem singular, peculiar. Porém, o que se tenta, a partir desse estudo, é pensar naquilo que Ramon é para além da síndrome, para além da "aberração cromossômica”, ou seja, para além do "modelo médico", como destaca Padilha (2000).

Nesse contexto, é importante dizer que a partir dos relatos de Marlene, das professoras e de nossas observaçóes, entendemos algumas nuances do "temperamento" do Ramon. Em muitos aspectos, observamos que Ramon assimilou e internalizou social e culturalmente alguns comportamentos de seus pares, o que é diferente daquilo que se é divulgado e ensinado sobre a síndrome no "modelo médico".

Nesse mesmo caminho, destaca-se que, quanto às características peculiares da síndrome, com relação à timidez e à dificuldade de socialização, Ramon apresentase como uma exceção. Gosta de trabalhar em grupo e gosta do movimento. Assim, percebemos a importância da não focalização nos caracteres que são típicos das síndromes. Se assim o fizermos, engessaremos nossas práticas e praticaremos a exclusão, em detrimento da inclusão que se refere à valorização de um sujeito potencial, com suas limitaçóes, mas rico em subjetividades e potencialidades.

É importante dizer que muitas das características citadas anteriormente contradizem o que os estudos médicos tratavam como características dos "portadores daquela patologia”. Nesse contexto, não criticamos os laudos médicos, mas como estes têm sido utilizados nas escolas. Muitas vezes, pensa-se da seguinte maneira: Ele tem laudo, devemos passá-lo de ano! Somente isso tem sido feito por estes alunos: 
Passá-los de ano, de mãos em mãos. Jogando o problema para os outros profissionais. Infelizmente, o laudo não tem sido visto como disparador de possibilidades, mas sim como um anulador das potencialidades. A partir de nosso estudo, queremos enfatizar que no caso do Ramon, mesmo que o laudo tenha chegado nove anos depois do nascimento dele, esse 'papel' é um disparador em alguns espaços.

Isso evidencia que para além de ser um sujeito biológico, Ramon aprende e internaliza muitos comandos (a maioria deles, como ocorre com um sujeito sem síndrome, por exemplo) a partir das relaçóes dialógicas estabelecidas com os outros.

Sendo agora um pouco mais direto, o ponto a que estamos querendo chegar é o seguinte: Ramon, sujeito com a Síndrome de Klinefelter, APRENDE! De que ele precisa? De alguém que náo o carregue mais nos ombros (como alguns professores anteriores), de pessoas e profissionais que ensinem o caminho a ele e não deem a resposta pronta, de estimulação constante e, finalmente, de pessoas que acreditem, parafraseando Glat e Freitas (2002), que o sujeito com a síndrome de Klinefelter 'funciona' muito mais (pois possui muitas potencialidades, organicamente falando) do que se pensa, devido às barreiras que são impostas pelo seu laudo.

Por fim, no que tange ao título de nosso trabalho, ressaltamos que esse estudo traz à tona um sujeito para além do biológico. Um sujeito que possui seus déficits orgânicos impostos por sua constituição genética, por sua síndrome, mas que além e até antes disso é um ser que se relaciona com os outros e produz história e cultura. A sua constituição se dá a partir do outro e esse "eu" também influencia a construção social e cultural dos "outros".

\section{Referências}

ARAÚJO, M. P. M. A síndrome de Klinefelter: Caracterização e pressupostos inclusivos. Revista FACEVV, n. especial, 1. sem. 2012.

ARAÚJO, M. P. M. Para além do biológico, o sujeito com a Síndrome de Klinefelter. 2014. Dissertaçâo (Mestrado em Educação) - Programa de Pós-graduação em Educação, Universidade Federal do Espírito Santo, Vitória, 2014

CARRASQUINHO, J. et al. (2006). Síndrome de Klinefelter - Caso Clínico e Revisão da Literatura. Acta Urológica. Vol.23, n.3, pp.71-74. Disponível em <http://repositorio.hff.min-saude.pt/bitstream/10400.10/157/1/ Acta\%20Urol_13.pdf $>$. Acesso em 10 de ago. 2012.

DRAGO, R. Fracasso escolar e subjetividade: Análise e intervenção numa sala de aula. 1999. Dissertação (Mestrado em Educação) - Programa de Pós-Graduação em Educação, Universidade federal do Espírito Santo.

FREITAS, M. T. de A. A abordagem sócio-histórica como orientadora da pesquisa qualitativa. Cadernos de Pesquisa da Fundação Carlos Chagas. N. 116, jul. 2002.

GONZÁLEZ REY, F. O social na psicologia e a psicologia social. Petrópolis: Vozes, 2004.

GINZBURG, C. Mitos, emblemas e sinais: morfologia e história. Sáo Paulo: Companhia das Letras, 1989.

GLAT, R. Somos iguais a vocês: depoimentos de mulheres com deficiência mental. $2^{\text {a }}$ ed. Rio de Janeiro: 7Letras, 2009.

PADILHA, A. M. L. BIANCA O ser simbólico: para além dos limites da deficiência mental. 2000. Tese (Doutorado em Educação) - Programa de Pós-Graduação em Educação, Faculdade de Educação-Unicamp. Disponível em <http://www.brinquedotecavirtual.unopar.br/teses/bianca_o\%20ser_simbolico.pdf $>$ Acesso em: 23 de dezembro de 2013.

PARANÁ, D. O Filho do Brasil: de Luiz Inácio a Lula. São Paulo: Xamã, 1996. 
PINO, A. As marcas do humano. São Paulo: Cortez Editora, 2005.

REGO, T. C. Vygotsky: Uma perspectiva histórico-cultural da educaçáo. 21. ed. Petrópolis, RJ: Vozes, 2010. $139 \mathrm{p}$.

SMITH, C. M.; BREMNER, W. J: Klinefelter Syndrome. Arch Intern Med, 158:1309-1314, 1998.

SOUZA, S. J. e. Dialogismos e alteridade na utilização da imagem técnica em pesquisa acadêmica: questôes éticas e metodológicas. In: FREITAS, M. T. F.; SOUZA, S. J. e; KRAMER, S. Ciências Humanas e Pesquisa. 1. ed. São Paulo: Cortez, 2003.

THOMSON, A. Recompondo a memória. Questóes sobre a relação entre a história oral e as memórias. Projeto História. São Paulo, v.15, p. 51-84, 1997.

VICENTE, C. M. C. Estratégias para o desenvolvimento de competências comunicativas de uma criança com síndrome de Klinefelter. 2011. 121p. Dissertação (Mestrado em Ciências da Educação - Educação Especial). Escola Superior de Educação Almeida Garrett, Lisboa, Portugal.

VYGOTSKY, L. S. The problem of the environment. In: VAN DER VEER, R.; VALSINER, J. (Org.). The Vygotsky reader. Oxford, UK: Basil Blackwell, 1994. P. 338-354.

VIGOTSKI, L. S. Obras escogidas V- Fundamentos de Defectologia. Madrid: Visor Distribuiciones, 1997.

VYGOTSKI, L. S. A formaçáo social da mente. São Paulo: Martins Fontes, 2007.

VYGOTSKI, L. S., LURIA, A. R. Estudos sobre a história do comportamento: o macaco, o primitivo e a criança. Porto Alegre: Artes Médicas, 1996.

VYGOTSKY, L. S. Teoria e método em psicologia. São Paulo: Martins Fontes, 2004.

\section{Notas}

1 Hipogonadismo masculino primário é uma deficiência funcional dos testículos que acarreta insuficiência do desenvolvimento sexual, o que resulta na esterilidade masculina

2 É a secreção inadequada de testosterona pelos testículos

${ }^{3}$ Total ausência de espermatozoides no sêmen.

${ }^{4}$ Educação de Jovens e Adultos

${ }^{5}$ Se assim o fizéssemos, estaríamos ouvindo a história de vida de Ramon a partir de apenas um olhar, uma única perspectiva. Como defenderemos mais adiante, nesse estudo, pretendemos defender a ideia dos múltiplos olhares sobre uma situação descrita, pois o 'meu' olhar necessita ser completado pelo olhar do 'outro'.

${ }^{6} \mathrm{~A}$ pesquisa foi realizada no ano de 2013.

${ }^{7}$ Não podemos assegurar que o hipodesenvolvimento de Ramon é apenas uma característica da síndrome de Klinefelter. Isso porque o parto de Ramon foi muito atípico e demorado. Não sabemos ao certo se ocorreu falta de oxigenaçấo do cérebro.

\section{Correspondência}

Michell Pedruzzi Mendes Araújo - Universidade Federal do Espírito Santo. Av. Fernando Ferrari, 514. CEP: 29075-073. Vitória, Espírito Santo, Brasil.

E-mail: michellpedruzzi@yahoo.com.br - rogerio.drago@gmail.com

Correspondência em 19 de agosto de 2018

Final em 20 de março de 2018 